\title{
Introduction
}

\author{
Saul Shiffman
}

I'm happy to welcome you here on behalf of the Planning Committee. It's a pleasure to see this actually happening after almost a year of planning, and I'm looking forward to the next day and a half.

We have 2454 days left until the year 2000, at which point the national goals are to have a smoking prevalence of $15 \%$. We're now at roughly $25 \%$. Put another way, we are $81 \%$ of the way to the year 2000 from 1964, the year of the first Surgeon General's report, and we have cut smoking prevalence roughly by half. So we're doing pretty well but still have a bit further to go.

In this morning's panel, we'll be discussing where we're going and how we're going to get there in terms of smoking cessation. Procedurally, this panel and the panels that follow will have a principal speaker, in this case $\mathrm{Dr}$ Gary Giovino, who will give a talk of about 20 minutes, and we'll then follow that with comments from a group of panellists, about five minutes each, followed by an opportunity for open discussion between you and the panel, and between you and the speaker. Let me now introduce the panellists and Dr Giovino.

Dr Dileep Bal is currently the Chief of Chronic Diseases Control for the State of California Department of Health Services. Dr Bal has a hand in administering the monies generated by Proposition 99, which is a 25 cent sales tax on cigarettes, which generates about a hundred million dollars a year for smoking research and control activities.

Mr Glen Bennett is currently Coordinator of the National Heart, Lung and Blood Institute's Smoking Education Program, whose job it is to translate findings from intervention research into community action and education programmes; he was formerly the director of smoking intervention with the American Heart Association.

Dr Ellen Gritz is a long-time colleague of mine, although I hesitate to remind her in public that she and I first started working together a little over 20 years ago in Los Angeles. She is certainly one of the leading experts in smoking and smoking cessation, and has particular interests in smoking among women and in special populations.

Our last panellist, Dr Patrick O'Malley is Senior Study Director at the University of Michigan's Institute for Social Research, and he is a co-director of a very well-known study called Monitoring the Future, which is a continuing study of the lifestyles and values of American youth with quite a bit of focus on smoking and drug use.

And finally our speaker, Dr Gary Giovino, got his start in psychology as an undergraduate, was involved subsequently in clinical treatment of smoking and smoking cessation, graduated from psychology to epidemiology, where he got his degree, and is currently the chief of epidemiology at the Office on Smoking and Health, and he's been involved in projects too numerous and varied to mention on smoking and smoking cessation. Dr Giovino will be talking on trends in smoking cessation.
Smoking Research Group, University of Pittsburgh, Pittsburgh, Pennsylvania, USA S Shiffman

Office on Smoking and Health, MS K-50 National Center for

Chronic Disease

Prevention and Health

Promotion,

Centers for Disease

Control and

Prevention

Atlanta, Georgia

30333, USA

GA Giovino

DM Shelton

MW Schooley

* Dr Giovino delivered the presentation at the conference

\section{Trends in cigarette smoking cessation in the United States}

\author{
Gary A Giovino^, Dana M Shelton, Michael W Schooley
}

My job today is to update you on trends in cigarette smoking, and, more importantly, smoking cessation in the US; to examine recent patterns of quitting activity in the nation; and to discuss the issue of the 'hard-core' smoker. I will discuss cessation methods and a recent report in $\mathcal{F} A M A$ by Fiore and colleagues ${ }^{1}$ on this topic. I will end my discussion with a look at the opportunities for progress that are currently available.
Cigarette smoking kills more than 400000 Americans annually. ${ }^{2}$ It is the single most important preventable cause of premature mortality in the US. ${ }^{3}$ We can reduce this annual burden of suffering, as Dr Schelling pointed out, by preventing initiation and by increasing cessation.

The upcoming report of the Surgeon General will focus on preventing the initiation of tobacco use among young people. The 1990 


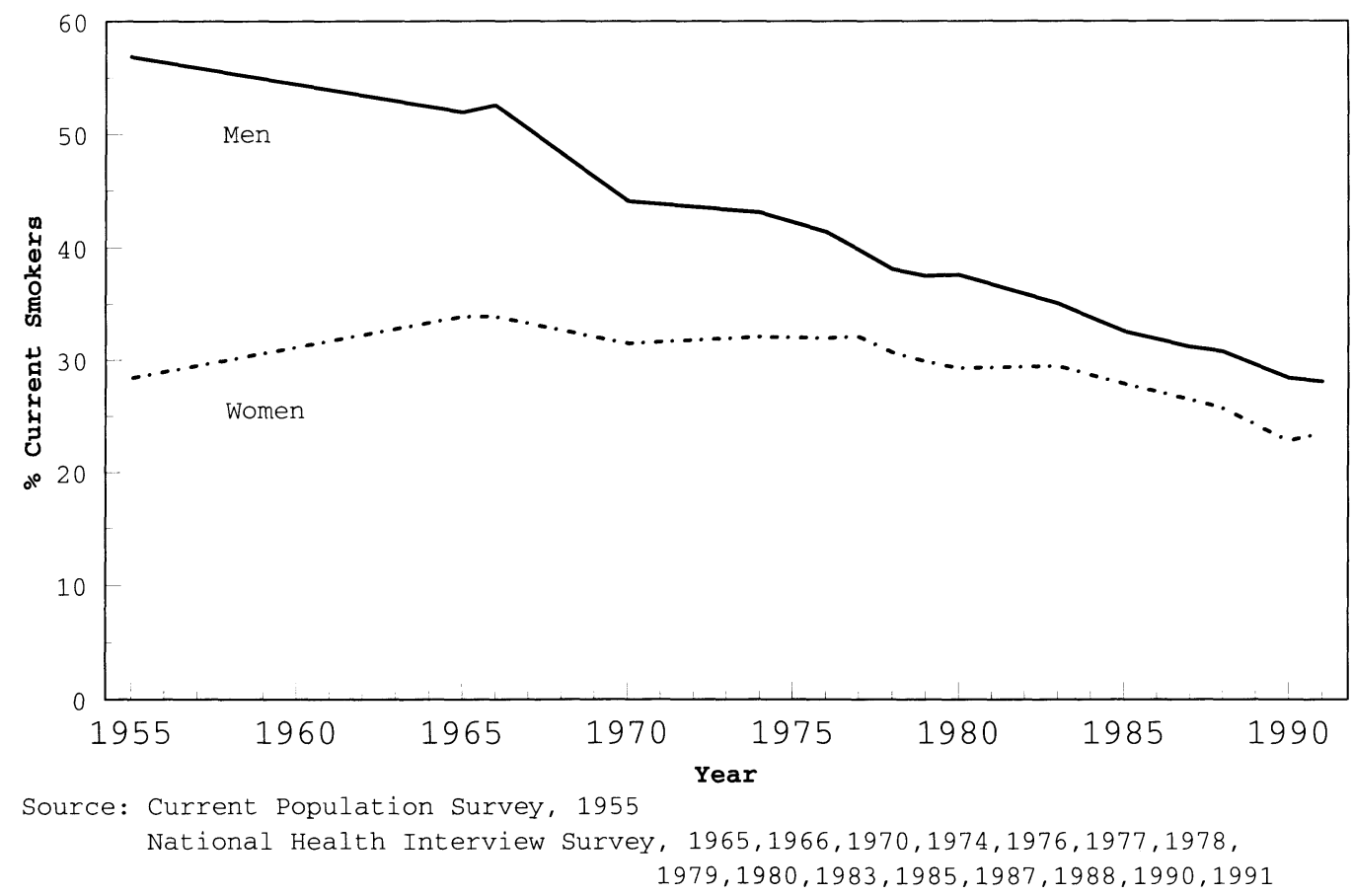

Figure 1 Trends in cigarette smoking prevalence among persons aged 18 years and older, by sex - United States, 1955-1991

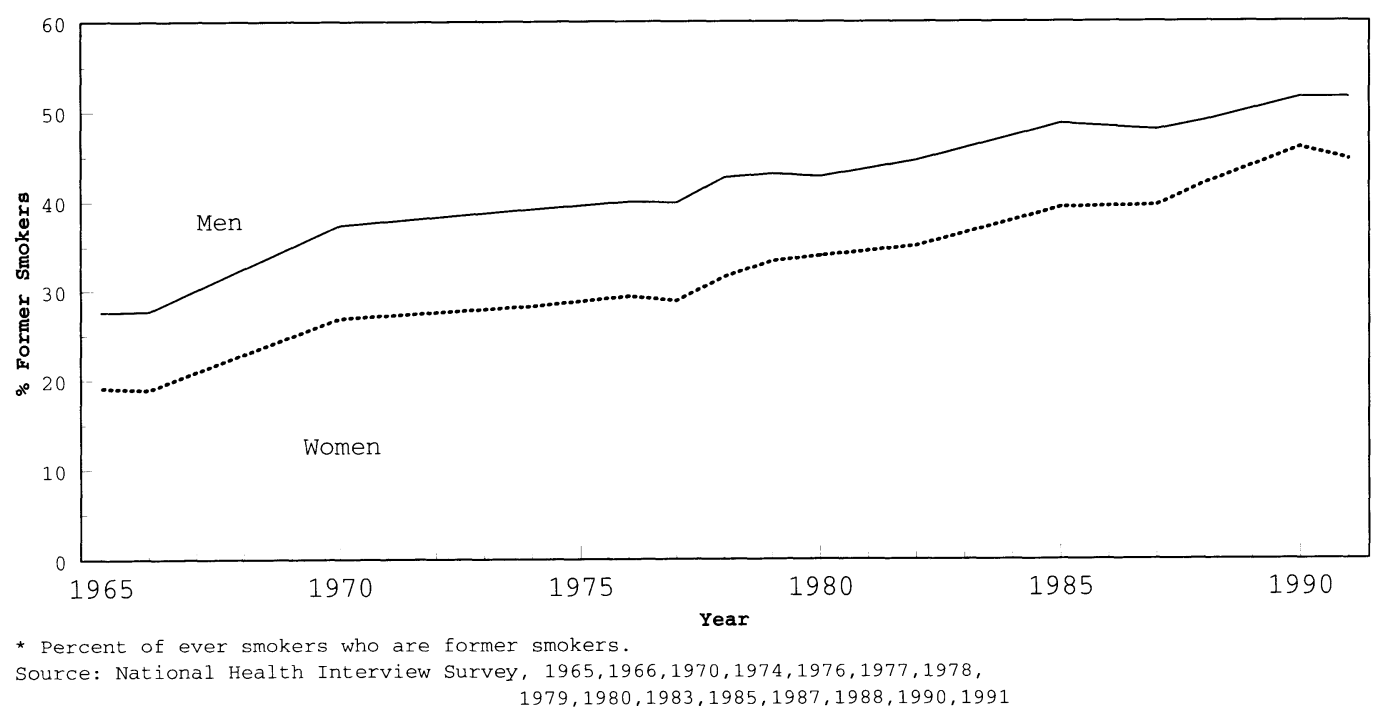

Figure 2 Trends in quit ratios ${ }^{\star}$ among persons aged 18 years and older, by sex - United States, 1965-1991

report of the Surgeon General addressed the health benefits of cessation and stated unequivocally that smoking cessation represents the single most important step that smokers can take to enhance the length and quality of their lives. ${ }^{4}$

The report demonstrated that smoking cessation has major and immediate health benefits for men and women of all ages; these benefits apply to persons with and without smokingrelated disease. There are benefits in terms of overall mortality. For example, former smokers live longer than do persons who continue to smoke. Persons who quit smoking before the age of 50 have half the risk of dying in the next 15 years than do persons who continue to smoke. Smoking cessation decreases the risk of lung and other cancers, heart attack, stroke, and chronic lung disease. It also has benefits in pregnancy. ${ }^{4}$

What is going on in terms of adult prevalence? We track prevalence in the nation using the National Health Interview Survey. This survey has tracked tobacco use since 1965 and it has used a fairly standardised method of measuring smoking behaviour. ${ }^{5-7}$ Many of you are aware of a recent $M M W R$ article that reported that 1991 was the first year since 1966 that we didn't see a decline in smoking prevalence. ${ }^{8}$ There wasn't an increase, I wouldn't interpret it as that, but prevalence didn't go down.

Year 2000 objectives have been established. ${ }^{9}$ If we project from where we are now in terms of prevalence in the country, we'll attain a current smoking prevalence of about 19 or 


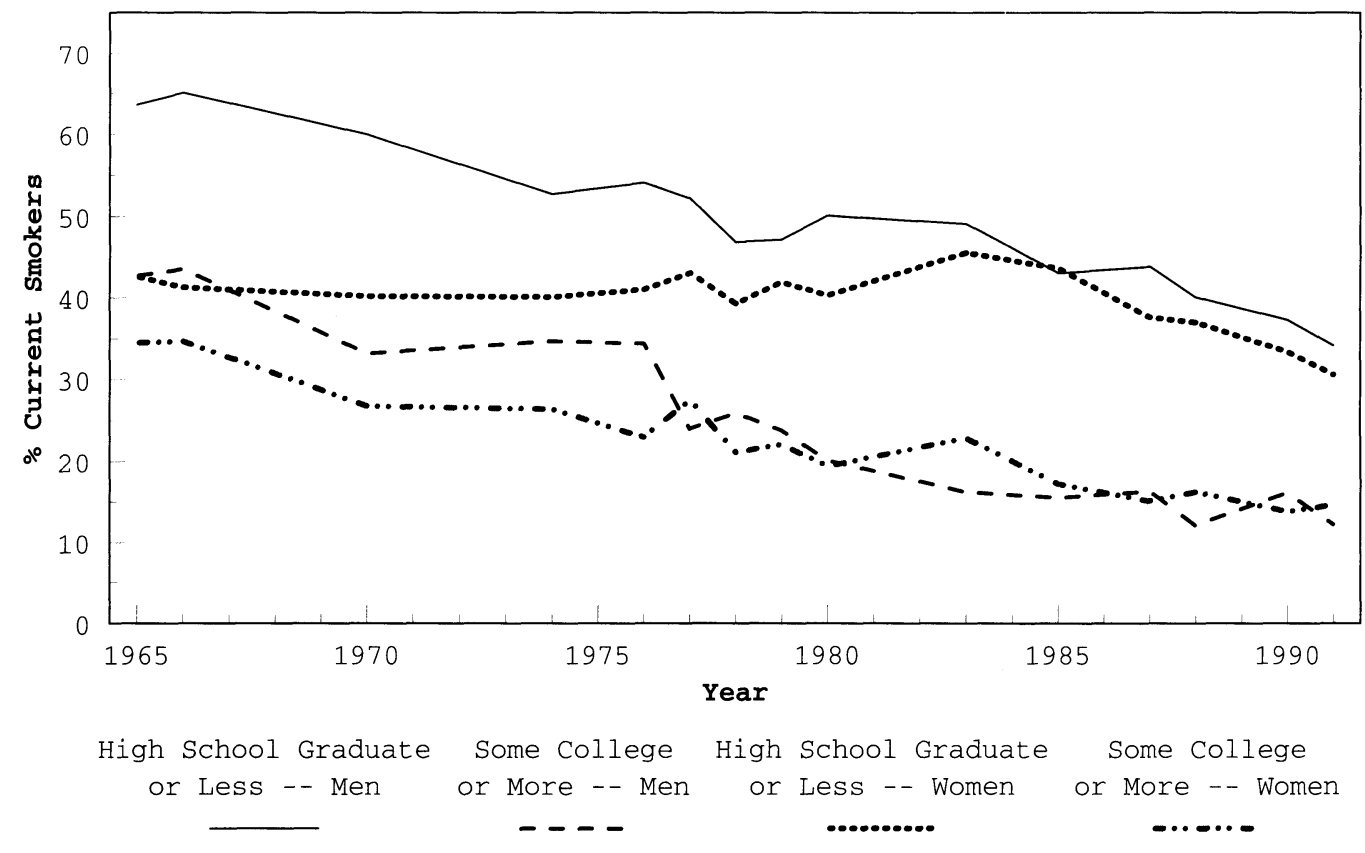

Source: National Health Interview Survey, 1965,1966,1970,1974,1976,1977,1978

Figure 3 Trends in cigarette smoking prevalence among persons aged 20-24 years old, by sex and educationUnited States, 1965-1991

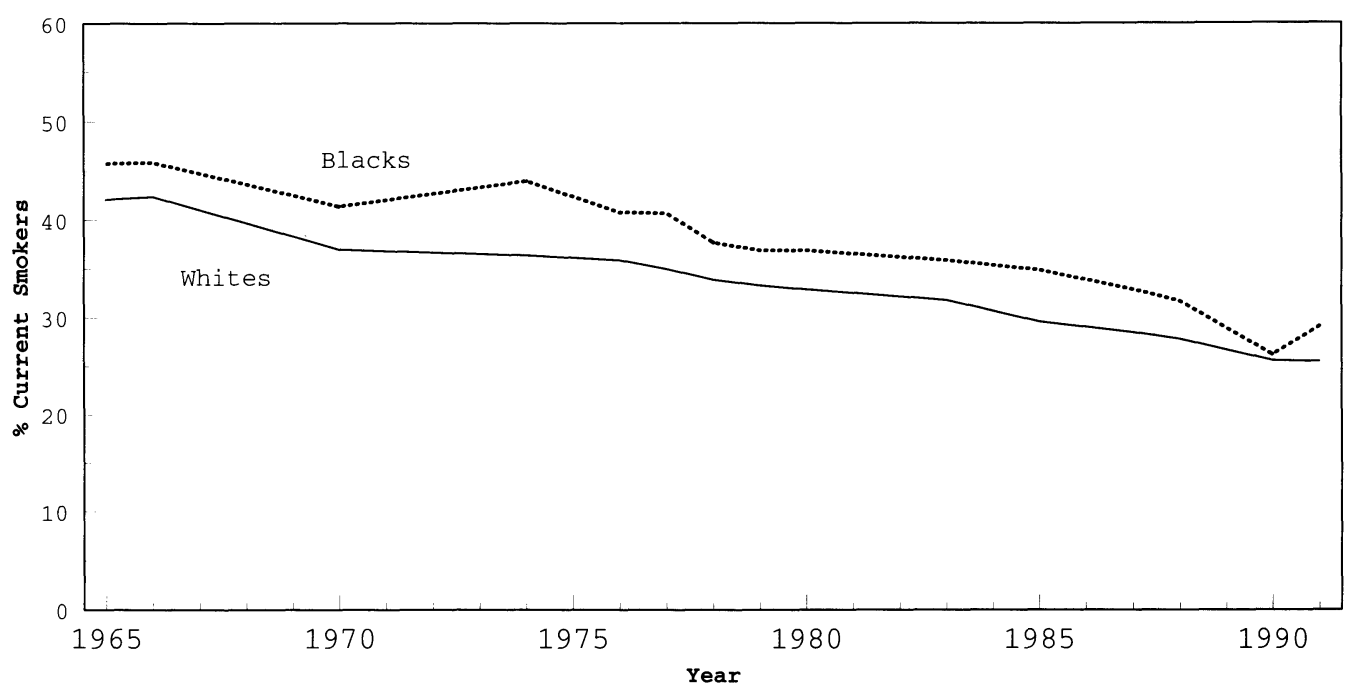

Source: National Health Interview Survey, 1965,1966,1970,1974,1976,1977,1978,

$1979,1980,1983,1985,1987,1988,1990,1991$

Figure 4 Trends in cigarette smoking prevalence among persons aged 18 years and older, by race-United States, 1965-1991

$20 \%$ by the year 2000 (Centers for Disease Control and Prevention [CDC], Office on Smoking and Health [OSH], unpublished data).

Rates of smoking among men and women have also declined, but the prevalence among men has declined more rapidly than the prevalence among women. As shown here, using data from the 1955 Current Population Survey, ${ }^{10}$ as well as the 1965 through 1991 National Health Interview Surveys, prevalence has consistently declined for men (figure 1). The prevalence of smoking among women was higher in 1965 than 1955, fairly level from
1965 to the late 1970s, and then declined somewhat.

In 1989, investigators used data collected from 1974 to 85 and projected that more women than men would be smoking by $1995 .{ }^{11}$ Given what's happened in recent years that's not going to happen if current trends continue. If anything, prevalence will be higher among women only after the year 2000 .

We're seeing continuing increases in quitting. The quit ratio for both men and women is increasing (figure 2). This ratio is generally higher for men than for women, but if we take into account that men who stop smoking 


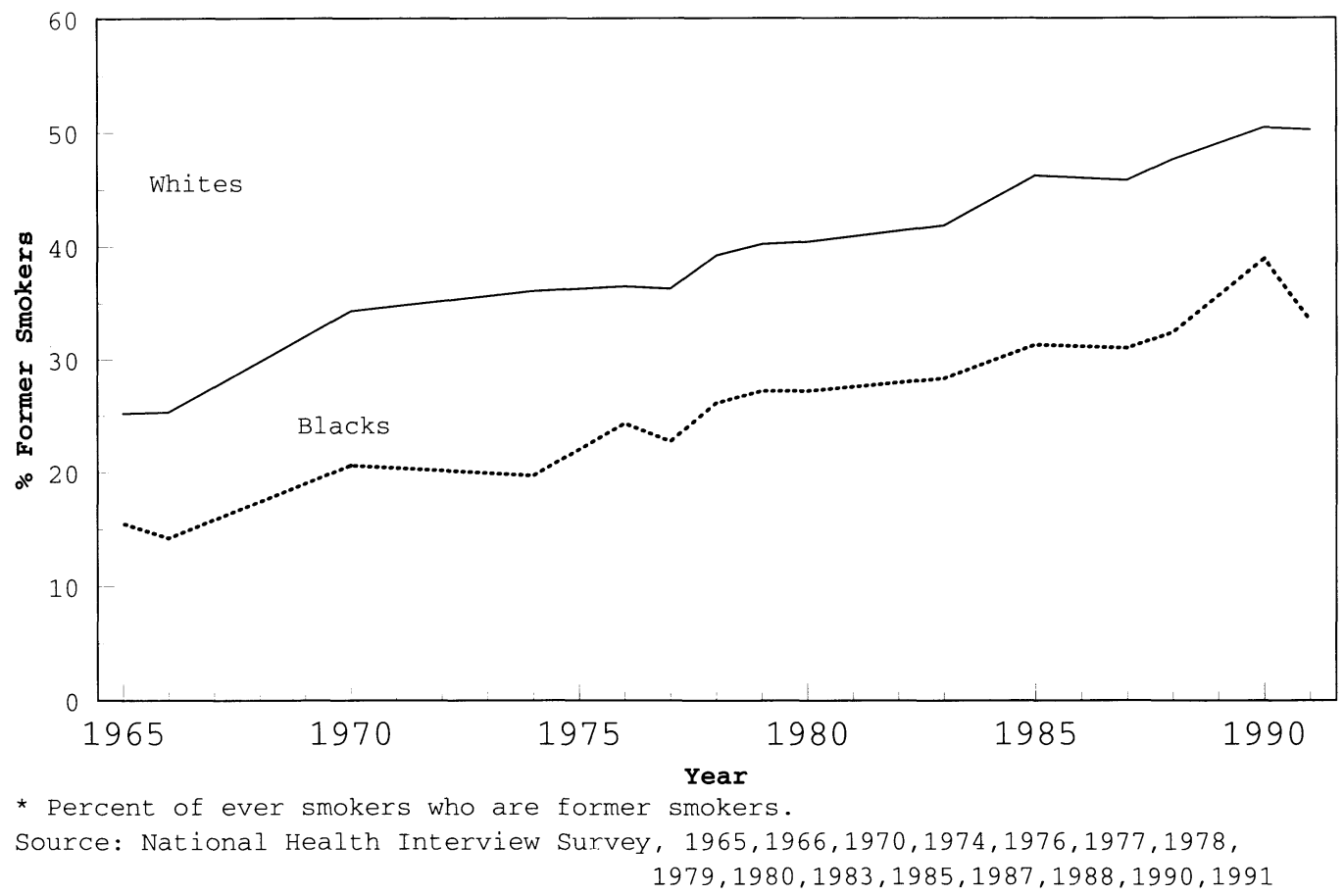

Figure 5 Trends in quit ratios ${ }^{\star}$ among persons aged 18 years and older, by race-United States, 1965-1991

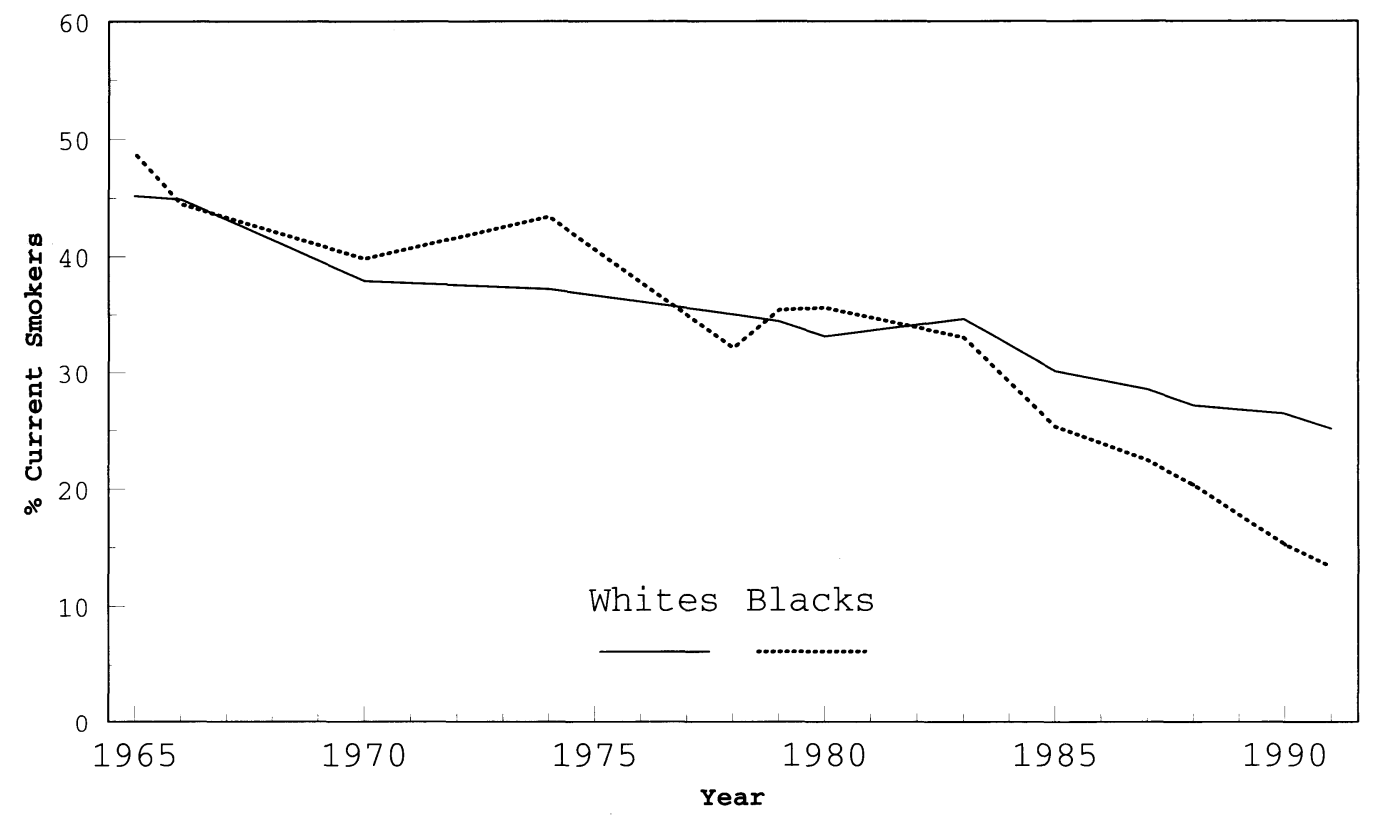

Source: National Health Interview Survey, 1965,1966,1970,1974,1978,

$1979,1980,1983,1985,1987,1988,1990,1991$

Figure 6 Trends in cigarette smoking prevalence among persons aged 18-24 years old, by race-United States, 1965-1991

cigarettes in this society are more likely than women to either switch to or to continue to use cigars, pipes, snuff or chewing tobacco, then this difference, which is about an eight percentage point difference, becomes about two percentage points ${ }^{4}$ (CDC, OSH, unpublished data). Again, we cannot lose sight of the fact that more and more women are quitting, just as more and more men are quitting.

The percentage of persons aged 20 to 24 years who are current smokers can be used as a marker for initiation. ${ }^{3}$ We have seen declines in initiation in this age group (figure 3). The big news from 1974 to 1985 was that there was no change in the prevalence of cigarette smoking among young women with a high school education or less. ${ }^{12}$ In fact, prevalence increased slightly from 1974 to 1985 among women aged 20 to 24 years with a high school education or less. As you can see in figure 3, this finding has changed. A sharp decline has recently been observed among this group of women. This is the biggest reason why, when we project out cigarette smoking prevalence, we can say that by the year 2000 , more men than women will still be smoking. Obviously, we want prevalence to go down as far as possible for both men and women. 
If we look at cigarette smoking among blacks and whites, prevalence among blacks has been consistently higher than among whites. In figure 4 you can see that the prevalence of cigarette smoking among blacks came down in 1990 and then went back up in 1991. The quit ratio is consistently higher for whites than for blacks (figure 5). This measure is, however, increasing for both races. For blacks there was an increase in the quit ratio from 1988 to 1990, followed by a sharp decline in 1991. We've looked at some of these data in a little more detail. John Horm, a statistician at the National Center for Health Statistics, hypothesises that all the controversy about the introduction of Uptown cigarettes ${ }^{13}$ led to either increased cessation in 1990 or a reluctance to report smoking behaviour in 1990 among blacks.

When we look at the data by quarter (CDC, $\mathrm{OSH}$, unpublished data), we see a sharp decline in prevalence among blacks between the first and second quarter of 1990 (Uptown was introduced in January 1990); then the prevalence rates tend to increase. At this point, how much of the decline is due to actual quitting and how much to misclassification is hard to say. In fact, we may never know, but clearly there's a very measurable phenomenon and one reasonable hypothesis is that it's due to Uptown.

We've also seen very sharp declines in the prevalence of smoking among young blacks, including among 18- to 24-year-olds (figure 6). Data on the nation's high school seniors are even more striking. ${ }^{14} \mathrm{We}$ 've seen declines again in prevalence among white adults aged 18 to 24 years, but the decline among black Americans in this age group has gone down very sharply.

The sociodemographic marker that's probably most strongly related to cigarette smoking prevalence is education. We know that prevalence among people with more formal education has dropped much more rapidly than among people with less formal education. College graduates show the lowest smoking prevalences and the sharpest declines. Prevalence among those who have gone to college and not completed it begins to decline after that of college graduates. Those who have just graduated from high school or not finished high school have the highest smoking prevalences. I don't believe that people get stopsmoking programmes in college; I think this phenomenon is due more to related psychosocial factors. People who go to college may be more open to the anti-smoking message and the message itself may be targeted, as Professor Schelling was saying. They may also have more opportunities and perhaps less stress in life, and they may have more role models who have quit smoking. The quit ratio is going up for all education groups, particularly college graduates. That it is going up for all education groups is something we shouldn't lose sight of.

So what is left? In 1991, 46 million US adults aged 18 years and older were current cigarette smokers. This figure represents about $26 \%$ of the population. Just to be thorough and estimate the number of people who are using nicotine-containing tobacco products, 4 million adults, or $2.5 \%$ of the population, were smoking cigars or pipes in 1991. Data from the 1991 National Health Interview Survey indicate that about 5 million adult Americans were using snuff or chewing tobacco. This figure represents about $3 \%$ of the population. Some of the people who use cigarettes also use cigars and pipes. In 1991, about 49 million Americans were smoking tobacco, and about 52.5 million Americans were using tobacco in any shape or form (CDC, OSH, unpublished data).

Another interesting trend showed up when we uncovered data from three national surveys on what smokers think of nicotine addiction. In 1978, the Roper Organization asked smokers if they thought cigarette smoking was a habit or an addiction. ${ }^{15}$ About $22 \%$ endorsed the answer that it's an addiction; another $15 \%$ said it was both.

In 1990 and 1991, the Gallup Poll asked smokers if they thought that they were addicted to cigarettes or not. In 1990, $61 \%$ of smokers reported that they thought they were addicted to cigarettes. ${ }^{16}$ By $1991,70 \%$ thought they were addicted to cigarettes. ${ }^{17}$ I think the 1988 Surgeon General's report ${ }^{18}$ has had an impact.

Using the 1991 National Health Interview Survey, ${ }^{19}$ I now want to discuss a recent study of quitting activity. In this survey, we asked people who had ever smoked 100 cigarettes what their smoking pattern was a year before. The question asked after 'Have you smoked at least 100 cigarettes in your entire life?' was 'Around this time last year were you smoking cigarettes every day, some days, or not at all?'.

The survey results showed that in 1991 there were 40 million people who had ever smoked 100 cigarettes who said that a year earlier they were smoking cigarettes every day. ${ }^{19}$ That number is lower than the 46 million current adult smokers because, actually, about one in six smokers are not everyday smokers, according to our latest data (CDC, OSH, unpublished data).

Of the estimated 40 million people who were everyday smokers in 1990, 37 million were daily smokers, 1.1 million were some-day smokers, and 2.5 million were former smokers in $1991 .{ }^{19}$ Among the people who were daily smokers in 1991, about 13 million quit smoking for at least one day during the study period (1990-91). These data demonstrate that an estimated 17 million people were abstinent from cigarettes for a day during this one-year period. Of those 17 million people, 2.5 million, or about $16 \%$, were abstinent at the end of the study period. ${ }^{19}$ Now, this is a cross-sectional survey. Some of those people, about $12 \%$, were off cigarettes for less than a month. Some, about $43 \%$, were off for between 1 and 6 months, and another $43 \%$ were off for 6 to 12 months (CDC, OSH, unpublished data).

The question can be asked, what percentage of people in any given year quit permanently? There are a couple of ways to estimate this percentage and we have to estimate it in the absence of good national longitudinal data. But if we consider the fact that, among these people 
who have quit smoking, many of them are going to relapse, and if we perhaps generously count the people who are off 6 months as staying off (and we all know that that's not totally true), then about 1.1 or 1.2 million people are abstinent. Thus, we could calculate that about $2.5 \%$ of the people who were smoking every day a year earlier would have remained off cigarettes.

Another estimate would consider that, during the 1970s and 1980s, there were about 50 million smokers in any year (CDC, OSH, unpublished data) and that the number of former smokers increased by about 1.3 million every year. ${ }^{11}$ Thus, again, about $2.5 \%$ of smokers quit each year. Not many people who are smoking quit for good in any given year, but the quit ratio is still increasing.

Currently, we have no national survey data from 1992, but we do have information on prescriptions for pharmacological aids. In 1992, about 6.5 million new prescriptions were dispensed for the transdermal nicotine patch and about a half million for nicotine gum (NPA PLUS*, IMS America Ltd, 1993). More prescriptions were dispensed for the patch in one year than for the gum in the first 4.5 years after the gum became available. The patch prescriptions were filled by about 3.5 million people (many of the 6.5 million prescriptions were filled when people switched from 21 to $14 \mathrm{mg}$ doses). That's a lot of people, and that number will increase the percentage of smokers getting face-to-face assistance. Even if the 17 million people whom I mentioned earlier quit without formal assistance, which is, of course, not true, and if we add another 3.5 million patch users, which hypothetically brings the total number of people who tried to quit in 1992 to over 20 million, then at least $15 \%$ of the people trying to quit smoking are getting face-to-face help from a physician. I think part of what we want to deal with in this conference is the quality of the instructions that are given and the quality of the compliance.

One important topic that Professor Schelling raised and that we all aware of is the hardcore smoker. What is a hard-core smoker? Is the residual population of smokers increasingly more hard core? Clearly there are dependent smokers in the US. The definition of the hardcore smoker would include people who smoke when they're sick, people who are heavy smokers, people who don't want to quit, people who may be addicted to other drugs, and, perhaps, people who are depressed. While all of those factors might be included in a definition of a hard-core smoker, we don't have all of these variables on any individual national survey.

In the 1986 Adult Use of Tobacco Survey, current smokers were asked whether they had ever thought about quitting and if they would quit if there was an easy way to do so. Sixteen percent of current smokers said that they had never thought of quitting, that they didn't want to quit, and that they wouldn't quit even if there was an easy way to do so. ${ }^{3}$ Now, if about one quarter of the adult population currently smokes and about $16 \%$ of smokers have absolutely no interest in quitting, then it's possible that cigarette smoking prevalence may decline to $4 \%$ some day (if those are the only people who are smoking now who would never quit).

There are clearly, though, dependent smokers out there, and I do not want to give the impression that there aren't. We used the 1991 National Household Survey on Drug Abuse to study self-reported indicators of nicotine dependency. ${ }^{20}$ That survey asked people who had smoked in the last year if they'd tried to cut down, if they'd tried but felt unable to cut down, and if they had felt that they needed or were dependent on cigarettes at all in the last year.

The number of cigarettes smoked per day is probably the strongest predictor of some of these measures. Heavier smokers (more than 25 cigarettes daily) are less likely to have tried to cut down. But even so, more than $60 \%$ of people who were smoking in the last year said that they tried to cut down. That's at least 35 million people. Among those who tried, about $90 \%$ of the heavier smokers and about $70 \%$ of the lighter smokers ( 1 to 15 cigarettes daily) said that they tried to cut down and felt unable to do so (CDC, OSH, unpublished data).

A high percentage of people - about $59 \%$ of lighter smokers and about $85 \%$ of heavier smokers-said that they felt they needed cigarettes or were dependent on cigarettes. There is no question that there are dependent smokers out there.

The question of what is happening over time has often been raised. We looked at the percentage of current smokers who smoked 25 or more cigarettes a day, by sex in this case, among adults 18 years old and older from 1974 to 91 . Among both men and women, there was little change in the percentage of smokers over time who smoke 25 or more cigarettes daily. In other words, the smokers who are left are not smoking more cigarettes a day.

We thought that the situation might vary by age, that perhaps there exists an older group of smokers who are digging their heels in. We looked at mean number of cigarettes smoked daily by age group and saw that there have really been declines for every age group, except for older smokers. The mean number of cigarettes smoked daily is increasing very slightly among older smokers. I don't think it's really hard evidence for an increase, though.

It's interesting that the mean number of cigarettes a day is low for older people and for younger people. I think that for younger people this is probably because they are still building up tolerance to nicotine and for older people it's because the people who are the heaviest smokers are no longer in the population because of differential mortality.

Another measure that might address the question of change over time is lifetime quitting activity. Among ever-smokers in $1978,26 \%$ had never tried to quit and $23 \%$ had quit previously but not in the past year. In $1990,21.5 \%$ had never tried to quit, and $15 \%$ 
had quit previously but not in the past year. $^{4}$

And, finally, Gallup has asked smokers for over a decade and a half, 'All things considered, would you like to give up smoking or not?' The number of smokers who report that they would like to quit has stayed between 63 and $76 \%$. In $1991,76 \%$ of current smokers stated that they wanted to quit, ${ }^{17}$ and the number hasn't changed much over time. Answering 'no' to this question is probably a socially unacceptable answer. We will need to consider that in our deliberations.

So if only one-quarter of smokers don't want to quit, and a quarter of a quarter is about $6 \%$, then another estimate of an eventual $6 \%$ smoking prevalence is conceivable. We may be able to start to think in terms of an eventual prevalence estimate of $4-6 \%$. This is optimistic; those people may be more likely to be using other drugs, and may be people who are poorer and less advantaged socioeconomically. ${ }^{21}$

People quit with various levels of assistance, ${ }^{1}$ but primarily on their own. A better way to put this would be to say that they quit without formal assistance. Nobody quits on their own. Everybody has motivational factors that come into play. By quitting on their own, I mean that they don't go out and get a self-help booklet, or attend a formal clinic. But there's so much motivation to quit smoking these days, so many people who are supportive, in good and bad ways, that nobody quits on their own. In the 10 years before 1986 , according to the paper that was published in $\mathcal{F} A M A$ recently, ${ }^{1}$ about nine out of 10 people who had quit smoking during those ten years did so without face-to-face assistance.

A lot of people quit smoking with self-help or minimal contact interventions: special filters or holders, or over-the-counter products. Cigarest was a product that sold 1.7 million packages in $1988 .^{22}$ From the latest Market Data research that I've seen, Cigarest is not selling many packages at all now. ${ }^{23}$ Life Sign is a little hand-held computer product that was on the market in $1988 .{ }^{22}$ According to Market Data, Life Sign is also not selling many products right now. ${ }^{23}$

Face-to-face intervention is the other intervention technique that people report and that, of course, includes programmes or courses, going to a doctor, and receiving pharmacological aids. Of course, 1992 is going to change the whole scenario.

In 1986, we documented that an assisted method of quitting was chosen by proportionally more women than men, more heavier smokers than light smokers, more collegeeducated persons, more middle-aged persons, and more of those with more previous quit attempts. ${ }^{1}$ I've seen some very limited market research data provided by one of the large pharmaceutical companies on the patch (Beta Research Corporation, unpublished data), and it appears, at least based on these limited data, that men and women are using the patch equally often and that education doesn't seem to be a predictor. Smokers who use the patch appear to be slightly older, at least over the age of 30, and have higher incomes than smokers who aren't using the patch.

I think the statement that most people who quit in the 10 years before 1986 did so without formal assistance has been used many times the wrong way, and I'd like to clarify some issues. First of all, we've seen, without a doubt, an increasing health care provider influence. Secondly, even unassisted quitters are influenced by numerous factors. Also, nicotine addiction is a chronic disease, and many people recycle. Although people who are addicted to nicotine may not use a programme on their successful quit attempt, they may have used one before or they may have come in contact with some help before. And even if $10 \%$ of the smokers use assisted methods, that is now almost 5 million people (M Fiore, personal communication, March 1993). That's a lot of people in need of help and, of course, it's the heavier smokers who are more likely to need the help. ${ }^{1}$ I want to add another statement: while most people who quit in the 10 years before 1986 did so on their own, most people who failed during that time did so on their own too. These people may have profited had they participated in some of the effective interventions that are now available.

There are some incredible opportunities out there. We can look at the percentage of people who were smoking in the year before they were surveyed in 1991, who visited a health care provider, and who were advised to quit. These data will probably change in 1992, but in 1991 36 million smokers or $70 \%$ of the smoking population, reported that they visited a doctor or other health care professional during the previous year. An estimated 13 million of these 36 million smokers, or $37 \%$, reported that they were advised to quit during that year $(\mathrm{CDC}$, $\mathrm{OSH}$, unpublished data). We all know the benefits of physician counselling and we all know the opportunity that the clinician's office presents. ${ }^{24}$

These data, by the way, vary slightly by age - as people age, they're more likely to be advised to quit. So too are the heavier smokers. White Americans are slightly more likely to be advised to quit smoking than are blacks and Hispanic Americans.

But there are other opportunities for accelerated progress. We can now look at a magazine and often see as many advertisements on quitting smoking (admittedly somewhat cryptic) as we can promoting the image of smoking. The Environmental Protection Agency report has raised new consciousness about the dangers of secondhand smoke. ${ }^{25}$ The possibility of increased excise taxes is looming on the horizon. Mass media campaigns are focusing on the dangers of smoking and the benefits of quitting. ${ }^{26}$

The Agency for Health Care Policy and Research is about to put together some clinical guidelines on smoking cessation that will lend some more legitimacy to cessation activity. We need to optimise these opportunities, and we must never forget that progress occurs one quitter at a time. We must use the phar- 
macological aids properly, never forgetting that they don't make someone want to quit and that they have to be given with proper instructions.

Let us discuss the needs of the millions of Americans who want to stop and who, in fact, wish they've never become addicted to cigarettes. ${ }^{16,17}$ Let us be wise and resourceful in our deliberations throughout this conference.

\section{Addendum:}

In April 1993 the Gallup Organization, Inc, conducted a national survey on US smoking prevalence, beliefs, and activities. ${ }^{27}$ That survey estimated that $66 \%$ of US smokers wanted to quit. This estimate is substantially lower than the $76 \%$ estimate for 1991 and may reflect a real change in the US population of smokers, perhaps indicative of an increasing proportion of 'hard-core' smokers. The estimate may also be attributable to other factors, including tobacco industry activities to bolster 'smokers rights'. Because fluctuations of similar magnitude have been noted since 1977 (the year Gallup started measuring this construct), the decline may be due to sampling variability. The survey estimates that in both 1977 and $1981,66 \%$ of smokers wanted to quit; the estimates for this measure were $75 \%$ in 1986 , $77 \%$ in $1987,68 \%$ in $1988,63 \%$ in 1989 , $74 \%$ in $1990,76 \%$ in 1991 , and $66 \%$ in 1993 . The trends in this measure should continue to be monitored. In $1993,74 \%$ of smokers considered themselves to be addicted to cigarettes. ${ }^{27}$

In a comment later in the proceedings (Session VI), Dr Rigotti wonders about the frequency of being advised to quit smoking as a function of the number of visits to a doctor or other health care provider during the previous year. We have subsequently run those data. In 1991 , among people ( $\geqslant 18$ years old) who had smoked during the previous year and reported only one visit to a doctor or other health care provider, $28 \%$ reported that they were advised to stop smoking; among those with two or three visits, $36 \%$ reported advice ; among those with at least four visits, $46 \%$ reported being advised to stop smoking during the previous year (CDC, OSH, unpublished data).

1 Fiore MC, Novotny TE, Pierce JP, Giovino GA, Hatziandreu EJ, Newcomb PA, et al. Methods used to quit States. Do cessation programs help? f $A M A$ 1990; 263: 2760-5.

2 Cigarette smoking-attributable mortality and years of potential life lost - United States, 1990 MMWR 1993; 42: 645-9.

3 US Department of Health and Human Services. Reducing the health consequences of smoking: 25 years of progress. A report of the Surgeon General, 1989. Atlanta, Georgia: Centers for Disease Control, Office on Smoking an Health, 1989. (DHHS Publication No (CDC) 89-8411.

4 US Department of Health and Human Services. The health benefits of smoking cessation. A report of the Surgeon General, 1990. Washington, DC: Department of Health and Human Services, 1990. (DHHS Publication No (CDC) $90-8416$.
5 National Center for Health Statistics. The statistical design of the Health Household Interview Survey. By the staff of
the US National Health Survey and the Bureau of the the US National Health Survey and the Bureau of the Census, US Department of Health, Education, and
Welfare, Public Health Service. Washington, DC: US Welfare, Public Health Service. Washington, DC: US 584-A2.)

6 Kovar MG, Poe GS. The National Health Interview Survey design, 1973-84, and procedures, 1975-83. Vital and health statistics. Series 1, No 18. US Department of Health and Human Services, Public Health Service, National Center for Health Statistics, 1985. (DHHS Publication No (PHS) 85-1320.

7 Massey JT, Moore TF, Parsons VL, Tadros W. Design and estimation for the National Health Interview Surveys, 1985-94. Vital and health statistics. Series 2, No 110. US Department of Health and Human Services, Public Health Service, Centers for Disease Control, National Center for Health Statistics, 1989. (DHHS Publication No (PHS) 89-1384.)

8 Cigarette smoking among adults-United States, 1991. MMWR 1993; 42: 230-33.

9 US Department of Health and Human Services. Healthy people 2000, national health promotion and disease prevention objectives. Washington, DC: Department of Health and Human Services, 1991. (DHHS Publication No (PHS) 91-50212.)

10 US Department of Health, Education, and Welfare. Tobacco smoking patterns in the United States: public health monograph No 45. Washington, DC: Office on Smoking and Health, HEW, 1955, (DHEW Publication No (HSM) 72-7508.)

11 Pierce JP, Fiore MC, Novotny TE, Hatziandreu EJ, Davis RM. Trends in cigarette smoking in the United States: RM. Trends in cigarette smoking in the United States:
projections to the year $2000 . \mathcal{F} A M A 1989 ; 261: 61-5$.

12 Pierce JP, Fiore MC, Novotny TE, Hatziandreu EJ, Davis $\mathrm{RM}$. Trends in cigarette smoking in the United States: educational differences are increasing. $\mathcal{F} A M A 1989 ; 261$ : $56-60$.

13 Robinson RG, Barry M, Bloch M, et al. Report of the Tobacco Policy Research Study Group on marketing and promotions targeted at African Americans, Latinos, and women. Tobacco Control 1992; 1(supp1): S24-30.

14 Bachman JG, Wallace JM, O'Malley PM, Johnston LD, Kurth CL, Neighbors HW. Racial/ethnic differences in smoking, drinking, and illicit drug use among American high school seniors, 1976-89. Am f Public Health 1991; 81: 372-7.

15 Roper. A study of public attitudes toward cigarette smoking and the tobacco industry in 1978, Vol 1. Roper Organization, May 1978.

16 Gallup G, Newport F. Many Americans favor restrictions on smoking in public places. Gallup Poll Monthly 1990; 298: 19-27.

17 Hugick L, Leonard J. Despite increasing hostility, one in our Americans still smokes. Gallup Poll Monthly December 1991.

18 US Department of Health and Human Services. The health consequences of smoking: nicotine addiction. A report of the Surgeon General, 1988. Washington, DC: Department of Health and Human Services, 1988. (DHHS Publication No (CDC) 88-8406.)

19 Smoking cessation during previous year among adults United States, 1990 M previous year among

20 US Department of Health and Human Services. National Household Survey on Drug Abuse: main findings 1991. Washington, DC: Department of Health and Human Services, 1993. (DHHS Publication No (SMA) 93-1980.)

21 Coambs RB, Kozlowski LT, Ferrence RG. The future of tobacco use and smoking research. In: Ney T, Gale A, eds. Smoking and Human Behavior. New York, NY: John Wiley \& Sons, 1989

22 Marketdata Enterprises. Stop smoking (smoking cessation) products and services: a market analysis, an investigation of historical, current, forecasted market potential, consumer demand, competitive methods, and products. Lynbrook, New York: Marketdata Enterprises, 1989.

23 Marketdata Enterprises. Stop smoking products and services: a marketing, demographic \& social analysis. Valley Stream, New York: Marketdata Enterprises, 1993.

24 US Preventive Services Task Force. Guide to Clinical Preventive Services : a report of the US Preventive Services Task Force. Baltimore, Maryland: Williams and Wilkins, 1989.

25 US Environmental Protection Agency. Respiratory health effects of passive smoking: lung cancer and other disorders. Washington DC; EPA, 1992. (EPA/600/6-90/006F.)

26 Pierce JP, Farkas A, Evans N, et al. Tobacco use in California 1992. A focus on preventing uptake in adolescents. Sacramento, California: California Department of Health Services, 1993.

27 Thomas RM, Larsen MD. Smoking prevalence, beliefs, and activities by gender and other demographic indicators. Princeton, New Jersey: The Gallup Organization, Inc, May 1993. 